\title{
Comparisons of Fastness of the Coating Processes of Electroless Silver Plating on Polyethylene Membrane Surfaces
}

\author{
YU Sheng, ZHANG Wen-jin, GENG Hui-ting, CHEN Yi-hu, \\ WANG Gui, WU Qiong, ZHU Xiao-xiao, ZOU Qi-hu \\ Lab of Environment and Analysis \\ Suzhou Vocational University \\ Suzhou, Jiangsu, P.R. China \\ e-mail: yus@jssvc.edu.cn
}

\begin{abstract}
The comparisons of fastness of the different coating processes of electroless silver plating on polyethylene membrane surfaces were investigated. The average fastness values of the impregnation (from 2.0 \pm 0.5 in I3-1 to $4.0 \pm 0.5$ in I2-1), the brush (from $4.0 \pm 0.3$ in B3-1 to $4.5 \pm 0.3$ in B2-1) and the spray (from $2.0 \pm 0.3$ in S3-1 to $4.0 \pm 0.3$ in S2-1) with adding the Tollen agent first and then the D-glucose which were more efficient processes (Figure 1) on fastness were $3.2 \pm$ 0.7 (TR-1), $4.2 \pm 0.8$ (TR-2) and $3.0 \pm 0.6$ (TR-3), compared with those of the impregnation (the average fastness value of $3.7 \pm 0.7$ in RT-1 from $3.5 \pm 0.3$ in $I 1-2$ to $4.0 \pm 0.3$ in I2-2), the brush (the average fastness value of $4.5 \pm 0.8$ in RT-2 from 4.0 \pm 0.3 in $\mathrm{B} 1-2$ to $4.5 \pm 0.3$ in B2-2) and the spray (the average fastness value of $3.3 \pm 0.4$ in RT-3 from $2.5 \pm 0.3$ in S3-2 to 4.5 \pm 0.3 in S2-2) with adding the D-glucose first and then the Tollen agent, and those of the impregnation ( $3.5 \pm 0.3$ in MS-1), the brush $(4.5 \pm 0.5$ in MS-2) and the spray (3.0 \pm 0.2 in MS-3) with the mixed solutions, respectively. Meanwhile, both the fastnesses of the D-glucose firstly and then the Tollen agent (Figure 2) and the fastnesses of the mixed solutions of the Tollen agent and the D-glucose (Table II) were not much different. The highest and lowest average fastness values of coating silver by different processes were the spray processes and the brush processes, respectively. Thus, the optimized coating processes of the electroless silver plating were the spray processes by adding the Tollen reagent and then the Dglucose to promote the adhesive values between the surfaces and silver element for the human beings health and the environment safety.
\end{abstract}

Keywords-component; formatting; electroless plating; polyethylene membrane; fastness

\section{INTRODUCTION}

Different from electroplating without use of external electric current through the solution and known as nongalvanic chemical plating, electroless plating in aqueous solutions is one of plating methods with several advantages versus electroplating such as free from flux-density and power supply issues providing an even deposit regardless of work-piece geometry and with the proper pre-plate catalyst depositing on non-conductive surfaces [1-3]. The several simultaneous electroless plating reactions are carried out when hydride ions from reducing agents (normally glucose) are released by producing negative charges on the solid substrates like the surfaces of the polymer plastics [4]. Although nickel, gold and copper coating layers can also be applied on polymer plastics as in the technique of gilding, one of the most common and not/no hazardous electroless plating methods on polymer plastics for foods and drugs is electroless silver plating because of the low electrode potential $\left(\varphi^{\theta}{ }_{\mathrm{Ag}+/ \mathrm{Ag}}=0.7996 \mathrm{~V}, 25^{\circ} \mathrm{C}\right)[2,5-9]$. By an autocatalytic chemical technique unlike electroplating as well, the electroless silver plating is to deposit the silver coating layer of Tollen-Reducing agent on the solid surface of the plastics. The process performed on the presence of a reducing agent of glucose (especially aldehyde groups) which deoxidizes the silver ions to deposit silver on nonconductive plastic polymers [10-12].

It is well known that polyethylene (PE) as one of the most common thermoplastic plastics with most having the chemical formula $\left(\mathrm{C}_{2} \mathrm{H}_{4}\right)_{\mathrm{n}}$ consists of long hydrocarbon chains. Due to differing in terms of the value of $n, P E$ is usually considered as the mixture of similar organic compounds and classified into several different categories based mostly on its density and branching. The end-use temperatures of $\mathrm{PE}$ are usually ranged from $-60^{\circ} \mathrm{C}$ to $120^{\circ} \mathrm{C}$ for preventing chemical and radical damages by strong acids or strong bases, gentle oxidants and reducing agents, and irradiations of sunlight and microwaves $[13,14]$. PE for both rigid containers and plastic film applications such as membranes is ordinarily with the high degree of short and long chain branching, meaning that the chains do not pack and have strong intermolecular forces of the instantaneousdipole induced-dipole attraction resulting in a lower tensile strength and increased ductility $[13,15]$. Therefore, the less intermolecular force may be one of the pathways that lead the surfaces of PE membrane roughened by the mechanical friction and chemical corrosion to possibly make metals deposited (especially for electroless silver plating) respectively by the processes of impregnation, brush and spray. Thus by chemical and mechanical roughening, those electroless processes can be involved for silver film coating easily with the help of the actions of Tollen-Reducing agent with the different fastnesses and conductivities on the PE membrane surfaces. Those outcomes are logical and obvious on the electroless silver plating by the different coating processes. 
Most modern anti-bacteria methods are to use several modifications of various compounds, classified on the basis of chemical/biosynthetic origin into natural agents like sorbic acids, organic agents like quaternaries, and inorganic agents like silver and its ion $[16,17]$. Those compounds are used to kill bacteria by bactericidal agents and slow down or stall bacterial growth by bacteriostatic agents according to their biological effect on microorganisms of biological activities. The well known inorganic agents are probably silver and its ion because of the safety to human beings in whole blood, plasma, serum, and urine. Consequently, silver added to reduce odors and the risk of bacterial and fungal infections can be used in foods and drugs embodying its use as an antibiotic coating in devices and containers [17]. Sometimes, silver can also inhibit the growth of bacteria and fungi on plastics, such as cling films and preservation bags. With applications in foods and drugs, fastness referring to the tendency of similar or identical particles or surfaces to cling to one another is very important. The forces of fastnesses can be named of chemical adhesion, dispersive adhesion and diffusive adhesion which are the intermolecular forces responsible for the function of various kinds of stickers and sticky tape into the categories [18, 19]. Among the cumulative magnitudes of these intermolecular forces, chemical adhesions of electroless coatings on PE membranes in general are most acceptable when the silver films and its ions adhere to the PE surfaces by ionic, covalent, hydrogen bonds and the network of those bonds $[6,15]$. It is mentioned that those attractive ionic and covalent forces are effective when the surfaces and the electroless coatings with the potential for chemical bonding need to be brought into very small distances, but also fairly brittle since the surfaces should be kept close together. It is thus clear that the strength of the fastness between the two materials depend on the two contracted surface areas. As one of the low surface energy materials, PE is also difficult to bond silver films without special surface preparations of the coating processes [15, 17].

Based on the consideration above, PE is approximately 80 million tones of the annual global productions with the mechanical properties depending significantly on varies of the extent and type of branching, the crystal structure and the molecular weight [14]. Silver are relatively safe for human beings compared with other metals coated on the PE membrane in our daily lives. Moreover, the variable capacitors are appeared of the highest quality when he PE membrane covers silver-plated plates. Similarly, silverplated membrane has other antistatic and anti-bacterial capabilities in plastic applications $[14,16]$. Consequently, the different processes of impregnation, brush and spray on electroless silver plating of PE membrane are necessary and important to be illustrated on the fastnesses of coating processes to be better for the human being health and the environment safety.

\section{Materials AND Methods}

\section{A. Chemicals and Instrument}

Silver nitrate (Aladdin, 99\%), sodium hydroxide (Aladdin, 98\%), ammonia (Aladdin, 25\%), alcohol (Aladdin, 99.8\%) and D-glucose (Aladdin, 99.5\%) were brought from Aladdin Industrial Corporation in USA. Distilled water (HPLC) as the solvent was involved for this work. The Tollen agent was made by ammonia solution of $5.5 \mathrm{wt} \%$ dropped into silver nitrate solution of $5.0 \mathrm{wt} \%$ until the precipitation was re-dissolved into solution under the sodium hydroxide concentration of $2.5 \mathrm{wt} \%$. Meanwhile, the reducing agent was mixed with D-glucose solution of $0.5 \mathrm{wt}$ $\%$ and ethanol of $0.8 \mathrm{wt} \%$. The PE membrane from super market was done by the processes of burring and leveling, then cut into pieces of $10.0 \mathrm{~cm} \times 10.0 \mathrm{~cm}$ and stored into glass boxes in darkness at the dry place $\left(25^{\circ} \mathrm{C}\right)$. The control was as the same processe without any further treatment on PE membrane surfaces.

\section{B. Experiment Method}

In the case of non-metallic substrate, the PE membrane pieces of $10.0 \mathrm{~cm} \times 10.0 \mathrm{~cm}$ was pretreated by the processes of deoil with $10 \%(\mathrm{~m} / \mathrm{m})$ dipotassium hydrogen phosphate at the ratio of $1: 1\left(\mathrm{~cm}^{2}\right.$ surface $/ \mathrm{g}$ solution) for $15 \mathrm{~min}$, chemical erosion with $5 \%(\mathrm{~m} / \mathrm{m})$ dichromic acid at the ratio of $1: 1\left(\mathrm{~cm}^{2}\right.$ surface/g solution) for $30 \mathrm{~min}\left(70^{\circ} \mathrm{C}\right)$, then rinse with distilled water twice at the flow ratio of $1.0 \mathrm{ml} / \mathrm{cm}^{2} \mathrm{~s}$ for $5 \mathrm{~min}$ to remove unwanted chemicals from the surfaces. The characteristics of the prepared PE membrane pieces were detailed in Table I.

TABLE I. PARAMETERS OF THE TEST POLYETHYLENE MEMBRANE SURFACES ON FASTNESSES OF COATING PROCESSES OF ELECTROLESS SILVER PLATING

\begin{tabular}{cc}
\hline \hline Surfaces & Test Piece \\
\hline Parameters & Odorless, colorless and transparent \\
\hline Appearance & Low density polyethylene (LDPE) \\
Material & $\geq 99.99$ \\
Purity $(\%)$ & $1.00 \pm 0.05$ \\
Thickness $(\mu \mathrm{m})$ & $1.10 \pm 0.05$ \\
Areal density $\left(\mathrm{mg} / \mathrm{cm}^{2}\right)$ & $-60-110$ \\
End-use temperature $\left({ }^{\circ} \mathrm{C}\right)$ & $\mathrm{CaCO}_{3}(<0.01 \mathrm{wt} \%)$ \\
Stuffing bulking agent & $12.0 \pm 1.3$ \\
Original surface roughness $(\mathrm{nm})$ & $102.2 \pm 1.1$ \\
Infiltration angle $\left({ }^{\circ}\right)$ &
\end{tabular}

The pretreated PE membrane pieces were divided into different groups for the processes of impregnation, brush and spray $(\varphi \leq 0.1 \mu \mathrm{m}, 3.0 \mathrm{MPa})$ and stretched into clean glass dishes, respectively. The experiments were including different ways of electroless silver plating on PE membrane surfaces. The way of Tollen agent firstly impregnated on PE membrane surfaces $\left(50.0 \mathrm{mg} / \mathrm{cm}^{2}\right.$ membrane) at $70^{\circ} \mathrm{C}$ for 2 min and then reducing agent was done by respectively impregnating, brush and spray on PE membrane surfaces $\left(100.0 \mathrm{mg} / \mathrm{cm}^{2}\right.$ membrane) at $70^{\circ} \mathrm{C}$ for $5 \mathrm{~min}$. The filmed PE membrane pieces were names as I1-1, I2-1 and I3-1, respectively. Thus, the processes of the ways that Tollen agent respectively brushed (named as B1-1, B2-1 and B3-1, 
respectively) and sprayed (named as S1-1, S2-1 and S3-1, respectively) firstly on $\mathrm{PE}$ membrane surfaces and reducing agent respectively impregnated (named as I1-2, I2-2 and I32 , respectively), brushed (named as B1-2, B2-2 and B3-2, respectively) and sprayed firstly on PE membrane surfaces were the same. The way of the mixed solution of Tollen agent and reducing agent $\left(150.0 \mathrm{mg}\right.$ mixed solution $/ \mathrm{cm}^{2}$ membrane) was respectively impregnated (MS-1), brush (MS-2) and spray (MS-3) on PE membrane surfaces at $70^{\circ} \mathrm{C}$ for $7 \mathrm{~min}$. Those named samples were carried out in 3 parallel examinations to measure the test error. The samples were air-dried $\left(70^{\circ} \mathrm{C}\right)$ for $8 \mathrm{~h}$ at the flow at ratio of 2.0 $\mathrm{ml} / \mathrm{cm}^{2} \mathrm{~s}$ to volatilize the distilled water as solvent and cleansed twice by absorbent cotton with distilled water to remove the more substances like free silver, then kept into darkness for determining the fastnesses of the coating processes of electroless silver plating on PE membrane surfaces.

\section{Fastness Detection}

The identification and quantification of coating fastnesses of electroless silver plating on PE membrane surfaces were performed using an Y571A hand color fastness friction instrument (American Standard). The rectangle friction head $(19.0 \mathrm{~mm} \times 25.4 \mathrm{~mm})$ was moved 10 times at the speed ratio of once per second in reciprocation of $104 \pm 3 \mathrm{~mm}$ with the vertical downward pressure of $9.0 \pm$ $0.2 \mathrm{~N}$ according to the national standard of GB/T 3920-2008. The evaluation criterion was checked with the national standard of GB/T 251-2008 (9 classes of grey scale for color assessment). Within each batch of the samples, one blank sample, the absence of a tissue sample in the glass vessel was then subjected to the whole experimental procedure to determine any analytical contamination.

\section{Data Analysis}

Each sample was tested at least twice with the hand color fastness friction instrument (American Standard) until the data could be acceptable. The data of these groups were operated by Microsoft Excel 2013 and one-way analysis of variance (ANOVA) with compare means test was checked for the evaluation of the data (SPSS v11.5 for Windows). The results were determined on the basis of homogeneous groups at the level of significance of $p<0.05$. All these calculated and analyzed data were pictured by Origin v7.5 Professional.

\section{Results AND Discussion}

\section{A. Fastnesses of the electroless silver plating processes of Tollen agent and then reducing agent on polyethylene membrane surfaces}

As a chemical reagent for electroless plating and consisted of the silver-amino complex solution of silver nitrate and ammonia, Tollen reagent could be precipitated of elemental silver in the presence of the aldehyde or alphahydroxy ketone groups in several organic matters on the PE membrane surfaces with a positive test of producing a characteristic "silver mirror" on the inner surfaces [1, 3]. Besides being used to apply a silver mirror to glassware, Tollen agent could also be coated on the surfaces of many plastic applications (PE membranes) with the help of the processes of electroless plating reduced by glucose (an aldehyde). For being freshly prepared in the laboratories, the Tollen reagent was not commercially available due to its short shelf life. It should be checked the utilities of the fastnesses of the electroless silver plating on PE membrane surfaces using Tollen agent firstly and then reducing agent [3].

In Figure 1, the coating processes of electroless silver plating on PE membrane surfaces by impregnation (TR-1), brush (TR-2) and spray (TR-3) of the silver-amino complex solution firstly were imaged in detail. The fastness values (from $2.0 \pm 0.3$ in S3-1 to $4.0 \pm 0.3$ in S2-1) of the significantly strongest coatings $(\mathrm{p}<0.05)$ were formed in TR-3 where the average fastness value was $3.0 \pm 0.6$. Furthermore, the fastness values (from $4.0 \pm 0.3$ in B3-1 to $4.5 \pm 0.3$ in B2-1) of the obviously weakest coatings $(p<$ $0.05)$ were shown in TR-2 where the average fastness value was $4.2 \pm 0.8$. The average fastness values of the other coatings shown in TR-1 (from $2.0 \pm 0.5$ in I3-1 to $4.0 \pm 0.5$ in I2-1) were $3.2 \pm 0.7$ (TR-1). It was purposed that superior silver films by electroless plating should get the silver-amino complex solution more even and sufficient coated on PE surfaces. Considered on the infiltration angle of $102.2 \pm 1.1$, the pretreated PE membrane surfaces were not soaked. The processes of brush would not firstly cover the silver-amino complex solution enough and evenly to avoid being gathered into drops and lines on PE membrane surfaces $[11,20]$. It resulted that the amounts of the deposition of the silver element on the PE surfaces were not homogeneous, meaning that the silver-amino complex might be reduced and covered more silver element in the gathered drops and lines where the extra silver element was piled up loosely on the previous matrixes. It seemed that the gathered drops and lines of the silver films got more silver element than the maximum amounts of the matrix layers. Moreover, the processes of the brush would scratch the firstly extended silver-amino complex solution to strip the initial attachments of silver element $[20,21]$. By contrast, the finer vapors of spray $(\leq 0.1$ $\mu \mathrm{m}, 3 \mathrm{MPa}$ ) could be dispersed by the processes of spray and absorbed evenly by the PE surfaces. It meant that the amounts of silver element would be spread to cover the PE membrane surfaces, illustrating that more membrane surfaces could be adhered more widely and not to accumulate the drops and lines on the non-invasion surfaces of PE membrane surfaces. The coated silver with those processes could be well proportioned without destroying the initial attachments of silver element [22, 23]. That was the reasons that the fastness properties of electroless of silver plating by the processes of the brush were out of the consideration. Interpreted the pictures from TR-1 to TR-3 in Figure 1 again, the tendencies of the fastness values in each samples of electroless silver plating on PE surfaces were similar where the lowest and highest values were of the processes of the brush (the average value of $4.1 \pm 0.7$ ) and those of the spray (the average value of $3.0 \pm 0.8$ ). It was 
further illuminated that the processes of brush could not well coat the silver element on PE membrane surfaces with the effects of the bigger drops on the non-infiltrated surfaces and the slighter damages of the silver element renderings of the initial attachments [24]. Those complications did course the results of the outcomes in each picture of Figure 1, where it was directly evidenced that the fastness value of $4.0 \pm 0.3$ in B3-1 was much higher than the other two fastness values ( $2.5 \pm 0.3$ in $\mathrm{I} 3-1$ and $2.0 \pm 0.5$ in $\mathrm{S} 2-1$, respectively). Thus, the optimizations of the electroless silver plating were done by the processes of the spray of the Tollen reagent and then the spray of the reducing reagent on PE membrane surfaces.

\section{B. Fastnesses of the electroless silver plating processes of reducing agent and then Tollen agent on polyethylene membrane surfaces}

The examples of reducing agents included some active metals, electron-rich aldehyde, and D-glucose compounds. Being called the reductants or reducers, the reducing agents in this experiment were complex compounds that could donate some electrons to the above-mentioned Tollen agent in the electroless silver plating reactions. The both strong (positive oxidation potential) and weak (negative oxidation potential) reducing agents typically in one of the lower possible oxidation states were oxidized by losing electrons with oxidizers of fewer electrons [3]. With the molecular formula $\mathrm{C}_{6} \mathrm{H}_{12} \mathrm{O}_{6}$ whose five hydroxyl $(\mathrm{OH})$ groups were arranged in a specific way along the six-carbon back and known as the dextrose or grape sugar and one of the 16 aldose stereoisomers, D-glucose did occur widely in nature and be classed as a hexose of one sub-category of monosaccharides with 6 carbon atoms [25]. Thus, the good reducing agents tending to consist of atoms with a low electro-negativity would have the abilities of atoms or molecules to attract bonding electrons.

The coating processes of electroless silver plating on PE membrane surfaces by impregnation (RT-1), brush (RT-2) and spray (RT-3) of the reducing agent firstly were detailed in Figure 2. The fastness values (from $2.5 \pm 0.3$ in S3-2 to $4.5 \pm 0.3$ in S2-2) of the evidently strongest coatings $(p<$ $0.05)$ were formed in RT-3 where the average fastness value was $3.3 \pm 0.4$. Thereafter, the fastness values (from $4.0 \pm 0.3$ in B1-2 to $4.5 \pm 0.3$ in B2-2) of the sharply weakest coatings $(\mathrm{p}<0.05)$ were shown in RT-2 where the average fastness value was $4.5 \pm 0.8$. The average fastness values of the other coatings shown in RT-1 (from $3.5 \pm 0.3$ in I1-2 to $4.0 \pm 0.3$ in I2-2) were $3.7 \pm 0.7$ (RT-1). It had been illustrated that Dglucose did have the abilities of reducing the positive silver ions in Tollen agent back to the silver atoms and then being self-gathered into the nano-silver particles in solutions [25]. Duo to the chain reactions, the silver covered on $\mathrm{PE}$ membrane surfaces was absorbed by surface energies instead of chemical adsorptions in the processes of coating Tollen solutions first, illustrating there were much less forces between silver element and PE membrane surface. Beside the consequences discussed above, the amounts of the reducing agents were much more than the amounts of the Tollen agents causing that the reaction of the silver element converted back from the silver ions would be rapidly occurred. The silver atoms and particles might be completely rounded and isolated by D-glucose molecules onto PE membrane surfaces [26, 27]. As a result, the fastness values of reducing gent first were inferior to those of Tollen agent first by comparisons with the sample data in Figure 1 and Figure 2. Based on the data of each picture in Figure 2, the weakest fastness values of electrless silver plating with firstly adding reducing agent were also the processes of the brush the same as those of adding Tollen agent firstly. The another explanation was the fact that viscous reducing gent solution with D-glucose could be stabilized the silver particles and suspended in solutions to delay the sedimentation rate and keep silver element away from PE membrane surfaces [28, 29]. As the obvious results in each picture of Figure 2, the fastness value of $5.0 \pm 0.5$ in B3-2 was much higher than the other two fastness values $(4.0 \pm$ 0.3 in $\mathrm{I} 3-2$ and $4.5 \pm 0.3$ in $\mathrm{S} 2-2$, respectively). It was concluded that the conditions of the electroless silver plating with the processes of spraying the reducing reagent and then the Tollen reagent on PE membrane surfaces were checked in this experiment section.

\section{Fastnesses of the electroless silver plating processes of the mixed solution of Tollen agent and reducing agent on polyethylene membrane surfaces}

It was well known that the applications of silver mirror reactions requiring the highest optical qualities were occurred on cleaned and insulated surfaces such as PE membrane surfaces since it created nano-scale roughness and reduced the reflectivity when Tollen agent and D-glucose as reducing agent were put together in solutions [3, 30]. The processes to produce silver mirrors by Tollen agent and Dglucose on PE membrane surfaces included additional additives to increase adhesion and film resilience. Similar to the processes detailed above, the liquid PE membrane surfaces consisted of the two different distinct layers. The first layer was the highly textured surfaces of the matrix of features close to the stably contains, meanwhile the second layer covering liquid filled in the spaces between the features $[31,32]$. The silver element could be collected on the PE membrane surfaces by adsorptions and precipitations.

Checked the Table II, the fastness of the electroless silver plating with the mixed solutions by impregnation $(3.5 \pm 0.3$ in MS-1), brush (4.5 \pm 0.5 in MS-2) and spray (3.0 \pm 0.2 in MS-3) were respectively revealed. Those data of samples were not clearly less than the data of the processes of adding the Tollen agent firstly and then D-glucose (Figure 1), but not different from the data of the processes of adding the Dglucose agent firstly and then Tollen agent (Figure 2), respectively compared with every value of each $\mathrm{PE}$ membrane surface. Calculated by the measurement relations of the silver mirror reactions, the amounts of D-glucose (100 $\mathrm{mg} / \mathrm{cm}^{2}$ ) were much than the reaction demand amounts. It was cleared that the processes of impregnation, brush and spray with mixed solutions on PE membrane surfaces would have the priorities to coat the D-glucose solutions although some amounts of silver element could be involved onto the PE surfaces $[25,33,34]$. Therefore, the D-glucose solutions could delay and stop the coating processes of silver on the 
surfaces with the help of the properties of the viscosities and the forces between the first layer and the second layer explained above in the experiment.

TABLE II. Dry Fastness of Electroless Silver Plating with MiXed SOLUTIONS

\begin{tabular}{cccc}
\hline & MS-1 & MS-2 & MS-3 \\
\hline Dry fastness (Rate) & $3.5 \pm 0.3$ & $4.5 \pm 0.5$ & $3.0 \pm 0.2$ \\
\hline
\end{tabular}

\section{CONCLUSIONS}

The fastness of the different coating processes of the electroless silver plating on polyethylene membrane surfaces were tested in this work. It was found that the effects of the processes of adding the Tollen agent first and then the Dglucose (TR-1, TR-2 and TR-3) were obviously the best for the electroless silver plating on polyethylene membrane surfaces. The effects of both the processes of adding the Dglucose first and then the Tollen agent (RT-1, RT-2 and RT3 ) and the processes of the mixing Tollen agent and Dglucose (MS-1, MS-2 and MS-3) were not significantly different because of the first layer of the highly textured surfaces of the matrix of features close to the stably contains and the second layer covering liquid filled in the spaces between the features. Among the processes of impregnation, brush and spray, it was clearly evidenced that the fastness values of the spray processes were the highest. The fastness values of the brush processes were the lowest due to scratching the extended Tollen agent to strip the initial attachments of silver element. The fastness values of the impregnation processes were between those of the spray and those of the brush. Thus, the optimized processes of the electroless silver plating were done by the processes of the spray of the Tollen reagent and then the spray of the Dglucose on PE membrane surfaces for promoting the adhesive values between the surfaces and silver element to avoid the risks of the toxicities of the silver (heavy metal) separated from the polyethylene membrane surfaces to keep the human being healthy and the environment safe.

\section{ACKNOWLEDGMENTS}

This work is funded by Jiangsu Students' Platform for innovation and entrepreneurship train Project (201411054003Y). We also thank C. Liu and L. Yu for technical assistance.

\section{REFERENCES}

[1] H. Chang, C.H. Pitt, and G.B. Alexander, "Electroless Silver Plating of Oxide Particles in Aqueous Solution," Journal of Materials Science, vol 28, pp. 5207-5210, 1993.

[2] E. Webb, C. Witt, T. Andryuschenko, and J. Reid, "Integration of Thin Electroless Copper Films in Copper Interconnect Metallization," Journal of Applied Electrochemistry, vol 34, pp. 291-300, 2004.

[3] X. Geng, M. Li, L. Zhao, and P.W. Bohn, "Metal-Assisted Chemical Etching Using Tollen's Reagent to Deposit Silver Nanoparticle Catalysts for Fabrication of Quasi-ordered Silicon Micro / Nanostructures," Journal of Electronic Materials, vol 40, pp. 24802485,2011
[4] F.W. Campbell, and R.G. Compton, "The Use of Nanoparticles in Electroanalysis: An Updated Review," Analytical and Bioanalytical Chemistry, vol 396, pp. 241-259, 2010.

[5] J.J. Kim, H.W. Lee, V.V. Dabhade, S.R. Kim, W.T. Kwon, D.J. Choi, H. Kim, and Y. Kim, "Electro Magnetic Interference Shielding Characteristic of Silver Coated Copper Powder," Metals and Materials International, vol 16, pp. 469-475, 2010.

[6] T.N. Nekrasova, Y.I. Zolotova, O.V. Nazarova, M.L. Levit, E.I. Suvorova, A.K. Sirotkin, Y.G. Baklagina, E.V. Didenko, and V.D. Pautov, "Silver Nanocomposites Based on (Co) Polymers of 2-Deoxy2-Methacrylamido-D-Glucose, N-Vinylamides, and Aminoacrylates," Doklady Chemistry, vol 446, pp. 212-214, 2012.

[7] M.Q. Wang, J. Yan, S.G. Du, J.W. Zeng, W.P. Chang, Y. Guo, and H.G. Li, "Adsorption Characteristic of Copper Ions and its Application in Electroless Nickel Plating on a Hydrogel-Functionalized Poly (Vinyl Chloride) Plastic,” Journal of Materials Science, vol, 48, pp. 7224-7237, 2013.

[8] R. Chakraborty, and R. Das, "Metal-Assisted Porous Silicon Formation Using Solution Deposition of Nanoscale Silver Films," Journal of Optics, vol 43, pp. 350-354, 2014.

[9] N. Yusoff, A. Pandikumar, R. Ramaraj, H.N. Lim, and N.M. Huang, "Gold Nanoparticle Based Optical and Electrochemical Sensing of Dopamine,” Microchimica Acta, vol 182, pp. 2091-2114, 2015.

[10]I.B. Leonor, and R.L. Reis, "An Innovative Auto-Catalytic Deposition Route to Produce Calcium-Phosphate Coatings on Polymeric Biomaterials," Journal of Materials Science: Materials in Medicine, vol 14, pp. 435-441, 2003.

[11]M. Choi, D. Choi and D. Kim, "Magnetic Permeability Behaviors of FeCo Micro Hollow Fiber Composites," Electronic Materials Letters, vol 11, pp. 782-787, 2015.

[12]T. Deng, M. Li, Y. Wang, and D. Liu, "Development of Solid-State Nanopore Fabrication Technologies," Science Bulletin, vol 60, pp. 304-319, 2015.

[13]E.I. Rodriguez, and F.E. Filisko, "Thermal Effects in High Density Polyethylene and Low Density Polyethylene at High Hydrostatic Pressures," Journal of Materials Science, vol 22, pp. 1934-1940, 1987.

[14] K.Y. Rhee, T.Y. Oh, Y.N. Paik, H.J. Park, and S.S. Kim, "Tensile Behavior of Polyethylene Fiber Composites with Polyethylene Fiber Surface-Modified Using Ion Irradiation," Journal of Materials Science, vol 39, pp. 1809-1811, 2004.

[15]E. Smiechowicz, P. Kulpinski, B. Niekraszewicz, and A. Bacciarelli, "Cellulose Fibers Modified with Silver Nanoparticles," Cellulose, vol 18, pp. 975-985, 2011.

[16] M.A. Yasnaya, G.Y. Yurkov, B.M. Sinel'nikov, N.I. Kargin, and S.E. Khoroshilova, "Preparation of Silver Nanoparticles Stabilized on the Surface of Polystyrene Microspheres," Inorganic Materials, vol 45, pp. 19-22, 2009.

[17] S.C.G. Daniel, T.A. Sironmani, V. Tharmaraj, and K. Pitchumani, "Synthesis and Characterization of Fluorophore Attached Silver Nanoparticles," Bulletin of Materials Science, vol 34, pp. 639-643, 2011.

[18]J. García-Barrasa, J.M. López-de-Luzuriaga, and M. Monge, "Silver Nanoparticles: Synthesis through Chemical Methods in Solution and Biomedical Applications," Central European Journal of Chemistry, vol 9, pp. 7-19, 2011.

[19]Y. Mori, T. Tagawa, M. Fujita, T. Kuno, S. Suzuki, T. Matsui, and M. Ishihara, "Simple and Environmentally Friendly Preparation and Size Control of Silver Nanoparticles Using an Inhomogeneous System with Silver-Containing Glass Powder," Journal of Nanoparticle Research, vol 13, pp. 2799-2806, 2011.

[20]D.F. Grishin, and I.D. Grishin, "Iron-Based Catalytic Systems in Atom-Rransfer Controlled-Radical-Polymerization Processes," Polymer Science Series C, vol 57, pp. 32-64, 2015.

[21]L. Huang, M.L. Zhai, D.W. Long, J. Peng, L. Xu, G.Z. Wu, J.Q. Li, and G.S. Wei, "UV-Induced Synthesis, Characterization and Formation Mechanism of Silver Nanoparticles in Alkalic 
Carboxymethylated Chitosan solution," Journal of Nanoparticle Research, vol 10, pp. 1193-1202, 2008.

[22] J. Kleperis, G. Wójcik, A. Czerwinski, J. Skowronski, M. Kopczyk, and M. Beltowska-Brzezinska, "Electrochemical Behavior of Metal Hydrides," Journal of Solid State Electrochemistry, vol 5, pp. 229-249, 2001.

[23]R. Kozera, J.J. Bucki, A. Sałacińska,J. Bieliński, and A. Boczkowska, "Quantitative Image Analysis of Ni-P Coatings Deposited on Carbon Fibers," Journal of Materials Engineering and Performance, vol 24, pp. 3400-3406, 2015.

[24]Y. Liu, N. Liu, and X.Y. Tan, "Preparation of Microtubular Solid Oxide Fuel Cells Based on Highly Asymmetric Structured Electrolyte Hollow Fibers," Science China Chemistry, vol 54, pp. 850-855, 2011.

[25]I.I. Obraztsova, G.Y. Simenyuk, and N.K. Eremenko, "Effect of the Nature of a Reducing Agent on Properties of Ultradisperse Copper Powders," Russian Journal of Applied Chemistry, vol 79, pp. 1605$1608,2006$.

[26]N. Takeyasu, T. Tanaka, and S. Kawata, "Fabrication of 3D Metal/Polymer Microstructures by Site-Selective Metal Coating," Applied Physics A, vol 90, pp. 205-209, 2008.

[27] V. Suraja, Z. Yaakob, N. Binitha, A. Ebshish, and K. Ranjana, "Surface Capped Silver Nanoparticles over Anatase Titania: An Efficient Catalyst for Aromatic Nitration Reactions," Reaction Kinetics, Mechanisms and Catalysis, vol 105, pp. 361-371, 2012.
[28]X. Zhu, Y. Liu, J. Long, and X. Liu, "Electrochemical Migration Behavior of Ag-Plated Cu-Filled Electrically Conductive Adhesives," Rare Metals, vol 31, pp. 64-70, 2012.

[29] H. Zhang, S. Nagao, and K. Suganuma, "Addition of SiC Particles to Ag Die-Attach Paste to Improve High-Temperature Stability; Grain Growth Kinetics of Sintered Porous Ag," Journal of Electronic Materials, vol. 44, pp. 3896-3903, 2015

[30]T.P. Niesen, and M.R. de Guire, "Review: Deposition of Ceramic Thin Films at Low Temperatures from Aqueous Solutions," Journal of Electroceramics, vol 6, pp. 169-207, 2001.

[31]R.A. Young, M. Fujita, and B.H. River, "New Approaches to Wood Bonding a Base-Activated Lignin Adhesive System," Wood Science and Technology, vol 19, pp. 363-381, 1985.

[32] K. Pantleon, and M.A.J. Somers, "Microstructure and Texture of FreeStanding Cu-Line Patterns," Journal of Electronic Materials, vol 33, pp. 1363-1372, 2004.

[33]M.R. Mucalo, C.R. Bullen, M. Manley-Harris, and T.M. McIntire, "Arabinogalactan from the Western Larch Tree: A New, Purified and Highly Water-Soluble Polysaccharide-Based Protecting Agent for Maintaining Precious Metal Nanoparticles in Colloidal Suspension," Journal of Materials Science, vol 37, pp. 493-504, 2002.

[34] D Yu, W. Li, W. Wang, and J. Zhang, "Preparation and Properties of Copper-Silver Complex Plating on PET Fabrics," Fibers and Polymers, vol 16, pp. 23-30, 2015.
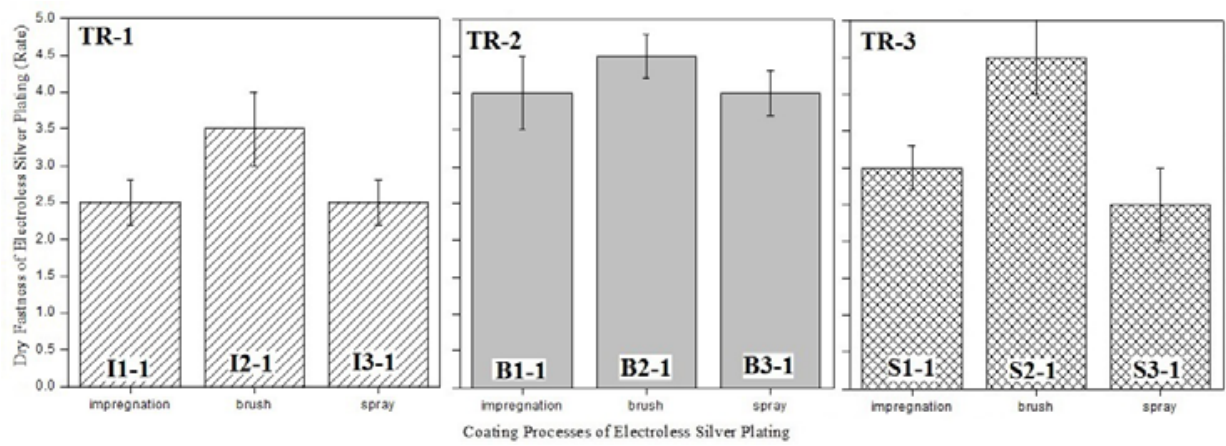

Figure 1. Fastnesses of the electroless silver plating processes of Tollen agent and then reducing agent on polyethylene membrane surfaces

The processes of impregnation ( $\square)$, brush $(\square)$ and spray ( $\square$ ) were carried out in the processes of impregnation (TR-1) first and then impregnation (I11), brush (I2-1) and spray (I3-1), brush (TR-2) first and then impregnation (B1-1), brush (B2-1) and spray (B3-1) and spray (TR-3) first and then impregnation (S1-1), brush (S2-1) and spray (S3-1) under the conditions of Tollen agent $\left(50.0 \mathrm{mg} / \mathrm{cm}^{2}\right.$ membrane) at $70^{\circ} \mathrm{C}$ for $2 \mathrm{~min}$, reducing agent $(100.0$ $\mathrm{mg} / \mathrm{cm}^{2}$ membrane) at $70^{\circ} \mathrm{C}$ for $5 \mathrm{~min}$, and the mixed solution of Tollen agent and reducing agent $\left(150.0 \mathrm{mg}\right.$ mixed solution $\left./ \mathrm{cm}^{2} \mathrm{membrane}\right)$ at $70{ }^{\circ} \mathrm{C}$ for 7 min, respectively.
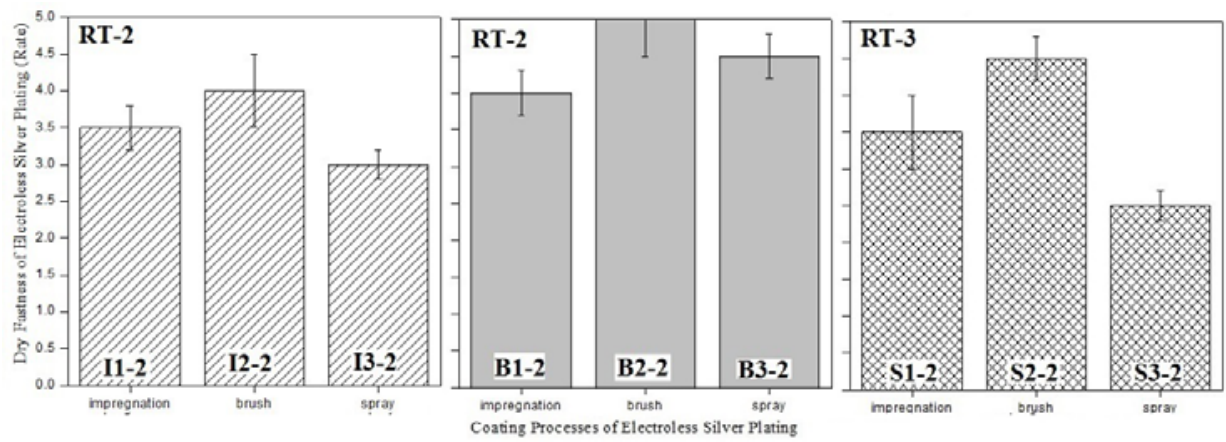

Figure 2. Fastnesses of the electroless silver plating processes of reducing agent and then Tollen agent on polyethylene membrane surfaces The processes of impregnation ( $\square$ ), brush $(\square)$ and spray ( $\square$ ) were carried out in the processes of impregnation (RT-1) first and then impregnation (I12), brush (I2-2) and spray (I3-2), brush (RT-2) first and then impregnation (B1-2), brush (B2-2) and spray (B3-2) and spray (RT-3) first and then impregnation (S1-2), brush (S2-2) and spray (S3-2) under the conditions of Tollen agent $\left(50.0 \mathrm{mg} / \mathrm{cm}^{2}\right.$ membrane) at $70{ }^{\circ} \mathrm{C}$ for $2 \mathrm{~min}$, reducing agent (100.0 $\mathrm{mg} / \mathrm{cm}^{2}$ membrane) at $70^{\circ} \mathrm{C}$ for $5 \mathrm{~min}$, and the mixed solution of Tollen agent and reducing agent $\left(150.0 \mathrm{mg}\right.$ mixed solution $\left./ \mathrm{cm}^{2} \mathrm{membrane}\right)$ at $70^{\circ} \mathrm{C}$ for 7 min, respectively. 